Disclosure of Interest: A. Tomelleri: None declared, C. Campochiaro: None declared, S. Sartorelli: None declared, C. Sembenini: None declared, S. Franchini: None declared, F. Motta: None declared, D. Vanni: None declared, G. Cavalli: None declared, E. Baldissera: None declared, L. Dagna Grant/research support from: The Unit has received unrestricted educational grants from Abbvie, BMS, Celgene, Mundipharma, Novartis, MSD, Pfizer, Roche, and SOBI.

DOI: 10.1136/annrheumdis-2018-eular.5220

\section{AB0648 CORRELATES OF FATIGUE IN ANCA-ASSOCIATED VASCULITIS}

A. Masiak ${ }^{1}$, K. Nowicka-Sauer ${ }^{2}$, A. Hajduk ${ }^{1}$, B. Grygiel-Górniak ${ }^{3}$, M. Komorniczak ${ }^{4}$ Z. Zdrojewski . ' Department of Internal Medicine, Connective Tissue Diseases and Geriatrics; ${ }^{2}$ Department of Family Medicine, Medical University of Gdansk,

Gdansk, ${ }^{3}$ Department of Rheumatology and Internal Medicine, Medical University of Karol Marcinkowski, Poznan; ${ }^{4}$ Department of Nephrology, Transplantology and Internal Diseases, Medical University of Gdansk, Gdansk, Poland

Background: Fatigue is a common symptom among patients with ANCA-associated vasculitis (AAV) identified as the greatest burden of their disease. ${ }^{1}{ }^{2}$ Research revealed associations between fatigue and bio-psychosocial factors but not with clinical factors.

Objectives: To assess fatigue and its correlates among patients with granulomatosis with polyangiitis (GPA) and microscopic polyangiitis (MPA).

Methods: 37 patients (44\% women; mean age 52.3 years; range 18-85) with GPA (27 patients) and MPA (10 patients) hospitalised in 3 clinical centres completed Multidimensional Fatigue Inventory-20 (MFI-20). ${ }^{3}$ Anxiety and depression were assessed by the Hospital Anxiety and Depression Scale (HADS). Sociodemographic data including age, sex, education, marital and occupational status were recorded. Disease characteristics included its' duration, severity, activity, organ involvement and laboratory data.

Results: The mean age was 52.3 years (range 18-85 years), and the mean disease duration was 43.1 months (range 1-248). 4 patients had limited type of the disease, 13 - early systemic, 16 - systemic and 4 - severe type of the disease. $75 \%$ of patients had active disease as defined by Birmingham Vasculitis Activity Score, BVASv3 (mean BVASv3 in active patients 12.2). $8 \%$ of patients were not taking steroids. $40,5 \%$ of patients had CRP $>5 \mathrm{mg} /, 43 \%$ had anaemia, $10 \%-$ thrombocytosis and $43 \%$ had renal insufficiency. Mean score of MFI-20 was 57 points (range 31-100). There were no differences in MFI-20 overall score between groups according to sex, education, marital and occupational status. No significant associations between fatigue and disease-related factors as well as steroid dose were observed. Depression $(r=0,79, p<0,00000)$ and anxiety $(r=0,63, p<0,00002)$ were strongly correlated with MFI-20 overall score.

Abstract AB0648 - Table 1. Socio-demographic characteristics of the study sample.

\begin{tabular}{lc}
\hline Variable & $\mathrm{n}(\%)$ \\
\hline Education & \\
primary & $6(16)$ \\
occupational & $3(8)$ \\
secondary & $12(32)$ \\
higher & $16(43)$ \\
Marital status & \\
married & $29(78)$ \\
divorced & $3(8)$ \\
free state & $4(11)$ \\
widower & $1(3)$ \\
Occupational status & \\
employed & $18(49)$ \\
unemployed & $3(8)$ \\
pensioner & $8(22)$ \\
annuitant & $5(13)$ \\
student & $3(8)$ \\
\hline
\end{tabular}

Conclusions: Since fatigue was not related to clinical characteristics, tiredness declared by the patient should not be interpreted as a symptom of active disease. There were no connexions between fatigue and socio-demographic variables. The strong association between fatigue and depression and anxiety levels indicates the necessity to supplement the standard drug therapy and/or cognitivebehavioural therapy aimed at reducing anxiety and improving mood.

\section{REFERENCES:}

[1] Basu N, McClean A, Harper L, et al. Explaining fatigue in ANCA-associated vasculitis. Rheumatology 2013;52:1680-1685.

[2] Herlyn K, Hellmich B, Seo P, et al. Patient-reported outcome assessment in vasculitis provides important data and a unique perspective. Arthritis Care Res 2010;62:1639-45.
[3] Buss T, Kruk A, Wiśniewski P, et al. Psychometric Properties of the Polish Version of the Multidimensional Fatigue Inventory-20 in Cancer Patients. J Pain Symptom Manag 2014;48:730-737

Disclosure of Interest: None declared DOI: 10.1136/annrheumdis-2018-eular.3554

\section{AB0649 USE OF BIOLOGICAL DMARDS IN PATIENTS WITH PRIMARY VASCULITIS; RESULTS FROM TURKBIO REGISTRY}

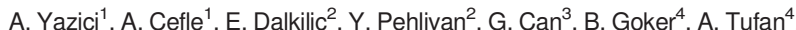
S. Senel ${ }^{5}$, S.S. Koca 6 , S. Akar ${ }^{7}$, N. Akkoç ${ }^{8}$, F. Onen ${ }^{9} .{ }^{1}$ Rheumatology, Kocaeli University School of Medicine, Kocaeli; ${ }^{2}$ Rheumatology, Uludag University School of Medicine, Bursa; ${ }^{3}$ Rheumatology, Dokuz Eylül University School of Medicine, Izmir, ${ }^{4}$ Rheumatology, Gazi University School of Medicine, Ankara;

${ }^{5}$ Rheumatology, Kayseri University School of Medicine, Kayseri; ${ }^{6}$ Rheumatology, Firat University School of Medicine, Elazig; ${ }^{7}$ Rheumatology, Katip Celebi University School of Medicine; ${ }^{8}$ Rheumatology, Private Practice; ${ }^{9}$ Rheumatology, Dokuz Eylül University School of Medicine, Izmir, Turkey

Background: Untreated, The systemic vasculitides can be devastating, with high rates of morbidity and mortality. Recently, most of biological agents have evaluated in clinical trials, and management of systemic vasculitis has been revolutionised over the last decade. ${ }^{12}$

Objectives: Here, we report the frequency of using and switching rate of biological agents in different types of primary vasculitis patients.

Methods: TURKBIO registry is the Turkish version of Danish DANBIO rheumatological database which has been established in 2011. All patients with primary vasculitis who received biological agents registered in TURKBIO registry between dates of October 2011 and January 2018 were included in this study. The demographic data, the date of starting to use of biological drug, frequency of using and switching biological agents were collected.

Results: As of January 2018, 108 primary vasculitis patients were recruited (mean age: $38.4 \pm 10.9$ [min-max: $19-67$ ]; female $48 \%$ ); 48 patients (44\%) of them had Behcet's disease (BH), $35(32 \%)$ had Takayasu arteritis (TA), $24(22 \%)$ had granulomatosis polyangiitis, and one of them had microscopic polyangiitis. The most commonly used biological agents in current treatment were as follows: $75 \%$ of patients received infliximab (INF) and $15 \%$ received adalimumab (ADA) in BD patients; $48.6 \%$ received tocilizumab (TCZ), $23 \%$ received INF and $20 \%$ received ADA in TA patients; all patients with granulomatosis with polyangiitis (GPA) were treated with rituximab. The switching rate was $54 \%$ in TA patients, $27 \%$ in BD patients, and $4 \%$ in GPA patients. The most frequent switching was found at INF (28/78) and ADA (9/23) which was the most commonly used agent in TA and BD. The lowest switching rate was TCZ (2/17) in TA patients (table 1).

Abstract AB0649 - Table 1. Demographical features and managements of patients with primary vasculitis

\begin{tabular}{|c|c|c|c|c|}
\hline n (\%) & $\begin{array}{l}\text { All Patients } \\
\mathrm{n}: 108\end{array}$ & $B D n=48$ & TA $n=35$ & GPA $n=24$ \\
\hline $\begin{array}{l}\text { Mean Age year mean } \pm s d \\
\text { (min-ma) }\end{array}$ & $\begin{array}{c}38.4 \pm 10.9 \\
(19-67)\end{array}$ & $\begin{array}{r}37 \pm 8.3 \\
(19-54)\end{array}$ & $\begin{array}{c}35.7 \pm 11.1 \\
(20-59)\end{array}$ & $\begin{array}{c}47.7 \pm 11.1 \\
(23-67)\end{array}$ \\
\hline Gender (F) & $52(48)$ & $11(23)$ & 32 (91) & 9 (37.5) \\
\hline Current Treatment & $19(18)$ & $2(4)$ & $17(49)$ & 0 \\
\hline Tocilizumab & $25(23)$ & 0 & 0 & $24(100)$ \\
\hline Rituximab & $2(2)$ & 0 & $2(6)$ & 0 \\
\hline Certolizumab & $44(41)$ & $36(75)$ & $8(23)$ & 0 \\
\hline Infliximab & $14(13)$ & $7(15)$ & $7(20)$ & 0 \\
\hline Adalimumab & $3(3)$ & $2(4)$ & $1(3)$ & 0 \\
\hline Etanercept & $1(1)$ & $1(2)$ & 0 & 0 \\
\hline \multicolumn{5}{|l|}{ Golimumab } \\
\hline $\begin{array}{l}\text { Last Drug Survival mean } \pm s d \\
\text { (min-max) (month) }\end{array}$ & $\begin{array}{l}25.2 \pm 17.9 \\
(2-88)\end{array}$ & $\begin{array}{c}26.8 \pm 16.2 \\
(3-77)\end{array}$ & $\begin{array}{c}28 \pm 21.7 \\
(2-88)\end{array}$ & $\begin{array}{l}22.3 \pm 15.9 \\
(2-60)\end{array}$ \\
\hline Switching Rate & $33(31)$ & $13(27)$ & $19(54)$ & $1(4)$ \\
\hline Tocilizumab & 3 & 0 & 2 & 1 \\
\hline Infliximab & 28 & 10 & 18 & 0 \\
\hline Adalimumab & 9 & 4 & 5 & 0 \\
\hline Etanercept & 4 & 3 & 1 & 0 \\
\hline
\end{tabular}

Conclusions: This is the first evaluation of primary vasculitis patients who used biological agents from TURKBIO registry. According our data, there was high switching rate with anti-TNF agents in TA patients. The limitation of this study was the low number of the patients with primary vasculitis who used biological agents.

\section{REFERENCES:}

[1] Jarrot PA, Kaplanski G. Anti-TNF-alpha therapy and systemic vasculitis Mediators Inflamm. 2014;2014:493593. 